\title{
Examining the face of aortic dissection outside the Western world
}

\author{
John A. Elefteriades, MD, ${ }^{\mathrm{a}}$ and Bulat A. Ziganshin, $\mathrm{MD}^{\mathrm{a}, \mathrm{b}}$
}

See related article on pages 2995-3000.

Aortic dissection is a challenging foe, having earned a well-deserved reputation as the great masquerader by virtue of the fact that its presentation can mimic a wide range of diseases. Dissection can present as myocardial infarction, stroke, paraplegia, leg ischemia, renal failure, and abdominal catastrophe-reflecting the fact that dissection can disrupt blood flow to any organ in the body (see Figure 1). As challenging as aortic dissection can be to recognize and treat, we have largely experienced the behavior of this disease only in the West. Variations around the world may contribute to even greater complexity than we have appreciated. Genetic, environmental, and social factors may produce differences in behavior of aortic dissection in other environments. The study by Wang and colleagues ${ }^{1}$ gives us a look at the face of acute aortic dissection in China.

Specifically, Wang and colleagues ${ }^{1}$ describe their new Registry of Aortic Dissection in China (Sino-RAD), which currently includes $>1000$ patients presenting acutely to 15 different centers across the country during a 2-year period. The authors provide a descriptive report of the patients included in Sino-RAD as well as a statistical comparison of clinical characteristics with the International Registry of Acute Aortic Dissection (IRAD). Establishing this nationwide database is a major accomplishment, and the authors are to be congratulated on this achievement as well as on their well-written report. This new information from China supplements the important work previously reported by Sun and colleagues ${ }^{2}$ describing their singlecenter experience treating $>450$ acute type A aortic dissection patients in Beijing.

Compared with IRAD (which represents aortic dissection patterns predominantly in Western countries), Sino-RAD, representative solely of Chinese patients with aortic dissection, reveals several distinctive features of this disease in China:

\footnotetext{
From the Aortic Institute at Yale-New Haven Hospital, ${ }^{\text {a }}$ Yale University School of Medicine, New Haven, Conn; and Department of Surgical Diseases \#2, ${ }^{\mathrm{b}}$ Kazan State Medical University, Kazan, Russia.

Disclosures: Authors have nothing to disclose with regard to commercial support. Received for publication Oct 4, 2014; accepted for publication Oct 6, 2014.

Address for reprints: John A. Elefteriades, MD, Aortic Institute at Yale-New Haven

Hospital, 789 Howard Ave, CB317, New Haven, CT 06519 (E-mail: john. elefteriades@yale.edu).

J Thorac Cardiovasc Surg 2014;148:3001-2 $0022-5223 / \$ 36.00$

Copyright (c) 2014 Published by Elsevier Inc. on behalf of The American Association for Thoracic Surgery

http://dx.doi.org/10.1016/j.jtcvs.2014.10.015
}

- Earlier age of onset,

- Substantial male predominance, and

- Relatively low incidence of hypertension.

Sun and colleagues ${ }^{2}$ also found presentation at a young age (mean age, 46.2 years) and male preponderance $(82.5 \%)$. However the experience of Sun and colleagues ${ }^{2}$ does not confirm a low incidence of hypertension $(73 \%$ hypertension, similar to the IRAD findings [67\%], but contrary to the Sino-RAD data [51\%]).

Several other observations in the article by Wang and colleagues $^{1}$ deserve comment.

The authors ${ }^{1}$ show a significantly lower in-hospital mortality for Sino-RAD patients compared with patients included in IRAD $(10.3 \%$ vs $27.4 \%)$. This comparison should be taken with a grain of salt. First, Sino-RAD data are being compared with IRAD data that were published 14 years ago. Significant improvements in diagnosis and treatment modalities have been made since that time. Second, as we know from our collaboration with Sun and colleagues, ${ }^{2}$ there is a certain natural selection that takes place in China: the sickest patients with an aortic dissection may not make it to hospital due to a lack of resources and/or large travel distances involved. Therefore, patients who do make it to hospital in China may already be self-selected for survival. This is in contrast to the experience in Western countries, where this access impediment is likely less prominent.

Another characteristic that stands out is the unusually high use of endovascular therapy in patients with acute type B dissection-almost $70 \%$ received a stent graft. Although endovascular therapy for type B aortic dissection is being increasingly investigated, we believe that such widespread application may be premature. We remain to be convinced that routine stent grafting for type B dissection produces substantial benefit above and beyond the complication-specific approach that we articulated nearly 25 years ago. ${ }^{3}$ The vast majority of type B dissection patients have a benign early and late course. A recent study by our group (unpublished data) confirms our original findings of good early survival $(87 \%)$, good late survival (51\% at 10 years), slow growth rate $(0.2 \mathrm{~cm} / \mathrm{y})$, and low need for late surgical intervention $(67 \%$ freedom from surgery at 10 years) with medical management in a complication-specific approach. Of course, there may be exigencies specific to China (such as poor compliance with follow-up regimens) that make early interventional therapy more appropriate than in Western environments.

The greatest potential of the Sino-RAD database will be found in realization of long-term follow-up. Wang and colleagues ${ }^{1}$ provide data on the in-hospital course only. The Chinese database will become immensely useful 


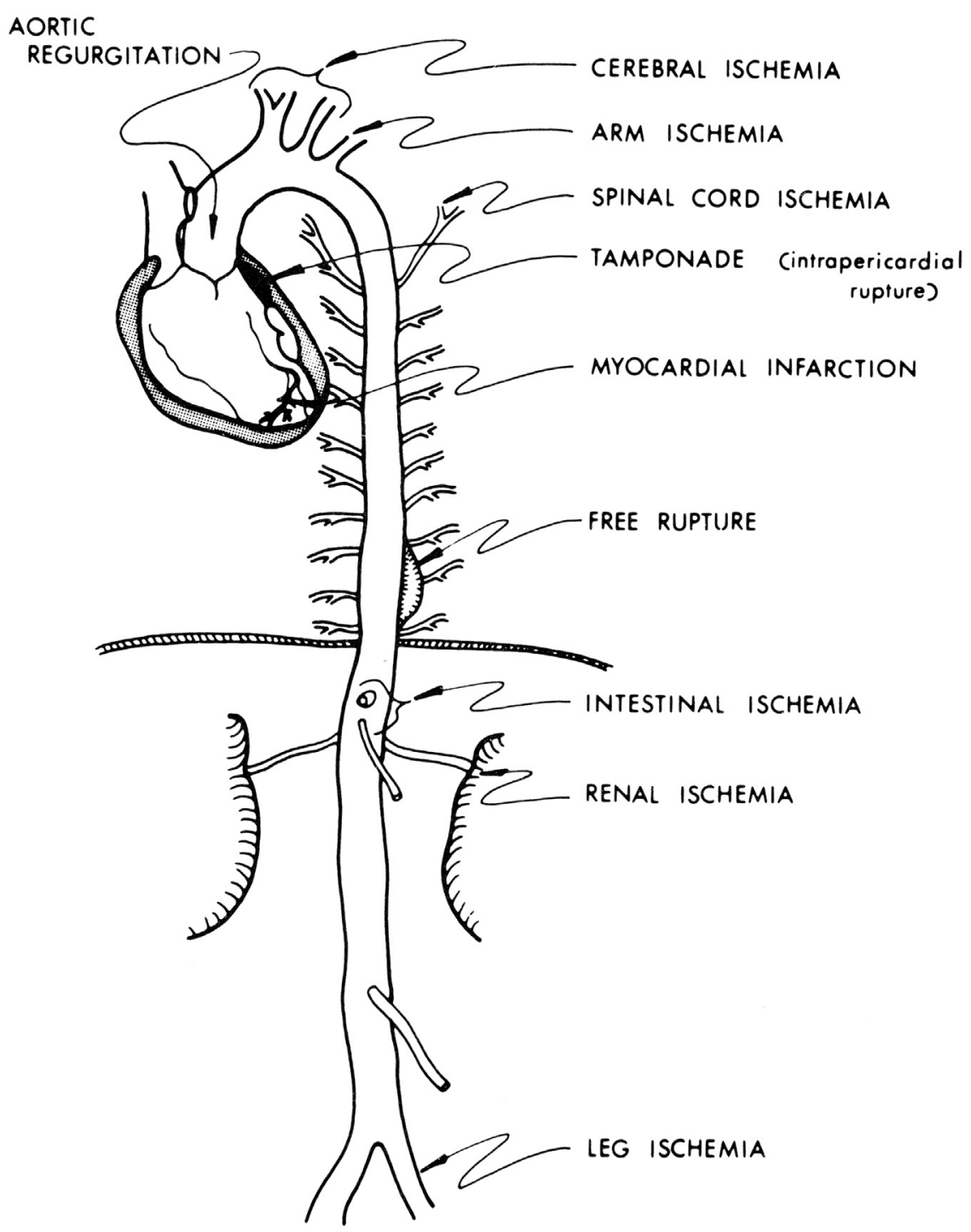

FIGURE 1. Schematic representation of various conditions that can be mimicked by aortic dissection. (Reprinted with permission from Elefteriades JA, Tribble C, Geha AS, Siegel M, Cohen LS. House officer's guide to ICU care: fundamentals of management of the heart and lungs. Minneapolis: CardioText; 2012.)

when long-term clinical and radiologic follow-up have been accomplished.

Wang and colleagues ${ }^{1}$ tell us that they set out to improve the diagnosis and treatment of acute dissection in China. Establishing this Sino-RAD database is a very meaningful first step. However, they fall short of clearly identifying how the current information will accomplish improvement in the diagnosis and treatment of patients with aortic dissection in China. We look forward to substantial clinical insights as this important work is taken forward.

Whether the Western/Chinese differences identified in the work by Wang and colleagues ${ }^{1}$ are related to genetic, environmental, or social factors remains to be determined. It is likely that genetic contributions to ethnic differences in behavior of aortic dissection will be clarified in the relatively near future, because whole exome sequencing is now being performed routinely at select centers in patients with thoracic aortic aneurysm and dissection. ${ }^{4}$

\section{References}

1. Wang W, Duan W, Xue Y, Wang L, Liu J, Yu S, Yi D. Clinical features of acute aortic dissection from the registry of aortic dissection in China. J Thorac Cardiovasc Surg. 2014;148:2995-3000.

2. Ma WG, Zheng J, Zhang W, Sun K, Ziganshin BA, Wang LF, et al. Frozen elephant trunk with total arch replacement for type A aortic dissections: does acuity affect operative mortality? J Thorac Cardiovasc Surg. 2014;148:963-70.

3. Elefteriades JA, Hartleroad J, Gusber RG, Salazar AM, Black HR, Kopf GS, et al. Long-term experience with descending aortic dissection: the complicationspecific approach. Ann Thorac Surg. 1992;53:11-20.

4. Ziganshin BA, Bailey AE, Coons C, Dykas D, Tanriverdi L, Liu L, et al. Comprehensive genetic screening for thoracic aortic aneurysm via whole exome sequencing. Abstracts of the Third GenTAC Thoracic Aortic Disease Summit. Baltimore, Maryland, July 9-10, 2014. 